\title{
Statistical scrutiny of Weibull parameters for wind energy potential appraisal in the area of northern Ethiopia
}

\author{
K. Shiva Prashanth Kumar ${ }^{1 *}$ and Satyanarayana Gaddada ${ }^{2}$
}

\begin{abstract}
Paramount two-parameter Weibull function has been extensively used to assess the wind energy potential. The performance contrast of four statistical methods, i.e., energy pattern factor method, least squares regression method, method of moments and mean standard deviation method in estimating extensively used Weibull parameters for wind energy application at four selected locations of northern Ethiopia has been studied. The contrast of statistical methods is compared through relative percentage error, root mean square error, mean percentage error, mean absolute percentage error, Chi-square error and analysis of variance (or) efficiency of the methods used. Test results evidently revealed that, least squares regression method presents better performance than other methods selected in the investigation. The least efficient methods to fit the Weibull distribution curves for the assessment of wind speed data especially for four selected locations are energy pattern factor method, method of moments and mean standard deviation. From the actual data analysis, it is found that if wind speed distribution matches well with the Weibull function, the above three methods are applicable, but if not, least squares regression method can be considered based on the cross checks including energy potential and cumulative distribution function.
\end{abstract}

Keywords: Wind energy, Weibull distribution, Probability distribution function (PDF), Cumulative distribution function (CDF), Shape parameter ( $k$ ), Scale parameter (c)

\section{Background}

Wind is one of the unlimited renewable energy resources which can provide with significant units of energy to bear the requirements of a nation. It is renowned that wind energy has stood out as the most precious and promising choice for generation of electricity. Earlier studies have proved that the installation of a number of wind turbine generators can effectively reduce environmental pollution, fossil fuel consumption, and the costs of overall electricity generation (Paritosh 2011). Though wind is only the sporadic source of energy which can represent a reliable energy resource from a long-term energy policy among the diverse renewable energy resources,

\footnotetext{
*Correspondence: prashanth1024@gmail.com

1 Department of Civil Engineering, College of Engineering

and Technology, Wollega University (WU), Nekemte, Oromia Region,

Ethiopia

Full list of author information is available at the end of the article
}

wind energy is one of the most admired energy resources around the globe.

In Africa, Ethiopia is among the least developed countries on the globe with a total access to electricity not exceeding $16 \%$. The country is endowed with all sources of energy such as hydro, solar, wind, biomass, natural gas, geothermal, etc., and has not been able to develop, transform and utilize these resources for optimal economic development. It has a capacity of generating electricity of more than $5000 \mathrm{MW}$ from geothermal and 10,000 MW from wind (Ethiopian Electric Power Corporation (EEPCo) 2011) and an average potential of $5.26 \mathrm{kWh}$ per square meter per day from high solar energy (Ministry of Water and Energy (MoWE) 2011). Wind power is growing globally at the rate of $30 \%$ annually, with an installed capacity increased from 196,653 MW in 2010 to 239,000 MW at the end of 2011 (World Wind Energy Association (WWEA) 2015). The Ethiopian government

\section{Springer}

(c) 2015 Kumar and Gaddada. This article is distributed under the terms of the Creative Commons Attribution 4.0 International License (http://creativecommons.org/licenses/by/4.0/), which permits unrestricted use, distribution, and reproduction in any medium, provided you give appropriate credit to the original author(s) and the source, provide a link to the Creative Commons license, and indicate if changes were made. 
is devoted to improving its energy production capacity as quickly as possible by constructing new power plants, expanding the national grid and has planned to reach 10,000 MW of installed capacities by 2015 (Ethiopian Electric Power Corporation (EEPCo) 2011). Lack of reliable wind data covering the entire country has been one of the reasons for limited application of wind energy in Ethiopia, but lately studies have shown that it has substantial potential to generate electricity from wind, geothermal and hydropower sources. Considering the substantial wind energy resource in the country, government has committed itself to generate power from wind plants by constructing eight wind farms with total capacity of $1116 \mathrm{MW}$ together with a number of hydropower plants over the 5 year Growth and transformation plan (GTP) period from 2011 to 2015. This development of wind power is a part of the current energy sector policy of the country that aims at five time's increase in renewable energy production by the end of 2015 (Mulugeta et al. 2013). Based on the theoretical cubic relationship for wind power estimation, it was found that the simplified approach may provide significantly lower estimates of wind power potential by 42-54\% (Yong et al. 2012). A feasibility study has been proven that the basic needs of the community are served by small Hydro/PV/Wind hybrid system for off-grid rural electrification in Ethiopia (Getachew and Getnet 2012). The analysis of solar energy potential and design of a hybrid stand alone electric energy supply system that includes a wind turbine, PV, diesel generator and battery (Bekele and Palm 2009).

Wind energy has intrinsic variances and hence it can be expressed by distribution functions. The Weibull distribution is an important distribution especially for reliability and maintainability analysis. Two-parameter Weibull distribution function has been commonly used in many folds which includes wind energy assessment, rainfall and water level prediction, sky clearness index classification, life length analysis of material, etc., for representing the picture of energy potential and feasibility of installing wind turbine systems (Abernethy 2002; Weibull 1939, 1951). Extreme transitions in wind speed characterization require specific efforts in investigating spatial, temporal and directional variation of wind speeds, which render rather difficult the characterization and classification of an area as of high or low wind potential, in the majority of cases (Bagiorgas et al. 2008). In recent times, it became a reference delivery in commercial wind energy software's resembling Wind Atlas Analysis and Application Program (Carta et al. 2009).

Enlargement of upgraded and innovative techniques for accurately assessing the wind energy potential of a site is gaining augmented importance. This is because of the fact that planning and establishment of a wind energy system depend upon factors like variation of wind speed distribution, mean wind speed, standard deviation, and characteristic operational speeds of turbine viz. cut-in velocity, rated velocity, and cut-out velocity. It is mandatory to amend the wind speed characteristics of a particular location to establish certain wind turbines for generation of electricity. Among the methods suggested by the prior researchers, it is bringing to crucial findings that the maximum likelihood method performs better than the popularly used graphical method in determining Weibull parameters; but the graphical method's performance can be enhanced as the bin size of wind speed is reduced (Seguro and Lambert 2000). The empirical method provides more accurate prediction of average wind speed and power density than the graphical method (Jowder 2009). Chi square method gave better estimations for Weibull parameters than the moment and graphical methods, based on the Kolmogorov-Smirnov statistics (Dorvlo 2002). The performances of maximum entropy principle (MEP) derived probability density functions (PDFs) in fitting wind speed data varies from site to site. Also, the results demonstrate that MEP-derived PDFs are flexible and have the potential to capture other possible distribution patterns of wind speed data (Junyi et al. 2010). A little difference in terms of adjusted $R^{2}$ and root mean square error (RMSE) values in modeling wind direction with angular-linear (AL) and Farlie-Gumbel-Morgenstern (FGM) approaches using bivariate statistical models for representing both wind direction and speed (Erdem and Shi 2011). Excellent fitting can be achieved for wind speed using conventional univariate probability distribution functions, but it is found that accurately fitting air density distribution of the North Dakota site can only be obtained using bimodal distributions (Xiuli and Jing 2010). All the geometric methods mentioned are based on the fact that wind speed data follow the Weibull probability distribution. However the wind data actually observed is not necessary with the Weibull distribution. For a given data set, widely used statistical methods such as moment method, least square regression method, standard deviation method, maximum likelihood method, modified maximum likelihood method and energy pattern factor method can be applied to estimate the Weibull parameters (Lai and Lin 2006; Zhou et al. 2006; Akpinar and Akpinar 2004; Celik 2003; Ucar and Balo 2009; Chang et al. 2003; Kwon 2010; Thiaw et al. 2010; Akdag and Dinler 2009).

The evaluation of Weibull parameters is so vital in wind energy application at a desired location. However, the precision of four statistical methods mentioned has been discussed in this current research. A very few studies have been performed to investigate the characteristics and pattern of wind speed across Ethiopia, less attention 
has been given to the sites principally in Northern Ethiopia. The main intention of this study is, therefore, to verify the performance of four statistical methods to analyze the Weibull parameters for wind energy applications at four selected locations (i.e., Chercher, Maychew, Mekele and Senkata) in the Northern Tigray region of Ethiopia.

\section{Data measurement}

The wind data used in this study was obtained from National Meteorological Agency (NMA), located at capital city of Tigray region, Mekele. The geographical coordinates of the meteorological stations where the wind speed data were captured at a height of $10 \mathrm{~m}$ by Belfordthree cup type anemometer are furnished in Table 1 . Care has been taken during the collection of data to avoid uncertainties and followed the methodologies proposed and explained in the ISO guide (International Standards Organization 1992). The uncertainty in the mean velocities at $95 \%$ confidence level was determined to be $\pm 2 \%$ (Manwell et al. 2010). Wind speed data used are observed per $3 \mathrm{~h}$ each day throughout the year from 2013 to 2014 at four different wind farms experiencing almost similar weather conditions. The recorded wind speeds were computed as the mean of wind speed for each month. It was noticed that using monthly wind speed has some limitations such as loosing extremely high or low wind speeds within the month as well as inability to observe diurnal variations in the wind speed. However, using the monthly mean wind speed, which is mostly available for all selected locations, can be used to study the seasonal changes in wind speed and facilitates wind data analysis.

\section{Methods for appraising Weibull parameters}

In the modern past, numerous statistical models have been developed and used for scrutiny of wind speeds for assessing energy potential at a location. Former studies have also been showed that a very few statistical methods such as Weibull and Rayleigh distribution models can also be equally used (Akpinar and Akpinar 2005). Among these methods, paramount two-parameter Weibull probability distribution function is one of the

Table 1 Geographical coordinates of selected experimental locations

\begin{tabular}{llllll}
\hline S. no & Stations & Longitude & Latitude & Altitude $(\mathrm{m})$ & $\begin{array}{l}\text { Measurement } \\
\text { period }\end{array}$ \\
\hline 1 & Chercher & $\mathrm{N} 12^{\circ} 53^{\prime}$ & $\mathrm{E} 39^{\circ} 76^{\prime}$ & 1767 & $2013-2014$ \\
2 & Maychew & $\mathrm{N} 12^{\circ} 47^{\prime}$ & $\mathrm{E} 39^{\circ} 32^{\prime}$ & 2479 & \\
3 & Mekele & $\mathrm{N} 13^{\circ} 29^{\prime}$ & $\mathrm{E} 39^{\circ} 28^{\prime}$ & 2084 & \\
4 & Senkata & $\mathrm{N} 14^{\circ} 13^{\prime}$ & $\mathrm{E} 39^{\circ} 34^{\prime}$ & 2480 & \\
\hline
\end{tabular}

most appropriate, conventional and suggested method for wind speed analysis owing to a better fit for measured monthly probability density distributions, than other statistical functions (Akdag et al. 2010). Moreover, the Weibull parameters at known heights can also be used to estimate wind parameters at a new height (Mathew 2006).

Weibull distribution function is described by the shape, scale, and threshold parameters. The case when the threshold parameter is zero is called the two-parameter Weibull distribution and it is depending on the values of its parameters and can take various forms. Due to its repetition from earlier researchers, the two-parameter Weibull probability distribution function has proven that the most appropriate, accepted and recommended distribution function for wind speed data analysis (Junyi et al. 2010). The variation in wind velocity is characterized by two parameter functions: probability density function (PDF) and the cumulative distribution function (CDF). The probability density function $f(v)$ indicates the probability of wind at a given velocity, while the corresponding cumulative distribution function $F(v)$ gives the probability that wind velocity is equal to or lower than $v$, or within a given wind speed range. The Weibull probability density function is given as, e.g., (Justus et al. 1978):

$$
f(v)=\frac{\mathrm{d} F(v)}{\mathrm{d} v}=\left(\frac{k}{c}\right)\left(\frac{v}{c}\right)^{k-1} \exp \left[-\left(\frac{v}{c}\right)^{k}\right]
$$

where $f(v)$ is the probability of observed wind speed $(v)$, $k$ is the dimensionless Weibull parameter and $c$ is the Weibull scale parameter $(\mathrm{m} / \mathrm{s})$. The scale parameter can be related to the mean wind speed $\bar{v}$ through the shape factor, which determines the consistency of wind speed at a given location.

The cumulative distribution, $F(v)$ is the integral part of probability density function, and can be expressed as, (Manwell et al. 2010):

$$
F(v)=\int_{0}^{v} f(v) \mathrm{d} v=1-e^{-\left(\frac{v}{c}\right)^{k}}
$$

The entire distributions can be used to resolve the probability of occurrence affects the shape of probability curve and wind regime. The cumulative curve probability nature typically fits to the Weibull distribution function. Copious methods for estimation of Weibull parameters are originated in the literature are furnished below.

\section{Energy pattern factor method (EPFM)}

The energy pattern factor is connected to the average data of wind speed and can be defined as the ratio of mean of cubic wind speed to the cube of mean wind speed. The energy pattern factor (EPF) can be expressed as: 


$$
\mathrm{EPF}=\frac{1}{\left(\bar{v}^{3}\right)}\left(\sum_{i=1}^{n} \frac{v_{i}^{3}}{N}\right)=\frac{\Gamma\left(1+\frac{3}{k}\right)}{\Gamma^{3}\left(1+\frac{1}{k}\right)}
$$

where $v_{i}$ is the wind speed in meter per second for $i$ th observation, $N$ is the total number of wind speed observations, and $\bar{v}$ is the mean wind speed. Once EPF is calculated, the Weibull shape and scale factors can be estimated from the following formulas:

$$
\begin{aligned}
& k=1+\frac{3.69}{(\mathrm{EPF})^{2}} \\
& c=\frac{\bar{v}}{\Gamma\left(1+\frac{1}{k}\right)}
\end{aligned}
$$

\section{Least-squares regression method (LSRM)}

LSRM is well known as a graphical method implemented by plotting a graph in such a way that the cumulative Weibull distribution becomes a straight line where the time-series data must be sorted into bins. The equation of PDF, after transformation and taking into consideration of natural logarithms both sides, the expression can be written as (Johnson and Kotz 1970):

$$
\ln [-\ln (1-F(v))]=k \ln v-k \ln c
$$

Equation 6 is linear and can be fitted using the following least square regression method: $y=a x+b$ with $y=\ln [-\ln (1-F(v))], x=\ln (v), a=k, b=-k \ln (c)$ and also

$$
k=a \text { and } c=e^{-\left(\frac{b}{k}\right)}
$$

The cumulative distribution function $F(v)$ can be estimated easily, using an estimator, which is the median rank, according to Benard's approximation:

$$
F(v)=\frac{i-0.3}{N+0.4}
$$

where $i$ is the number of the wind speed measurements and $N$ is the total number of observations (Benard and Bos-Levenbach 1953).

The relationship between $\ln (v)$ against $\ln [-\ln [1-F(v)]]$ represents a straight line with slope $k$ and the intersection point with Weibull line gives the value of scale parameter (c) in meters per second.

\section{Method of moments (MOM)}

MOM is one of the imperative techniques universally used in the field for evaluating Weibull parameters. It is based on the numerical iteration of mean wind speed $(\bar{v})$ and standard deviations $(\sigma)$ of wind speeds are expressed: where

$$
\begin{gathered}
\bar{v}=\frac{1}{n} \sum_{i=1}^{n}\left(v_{i}\right) \text { and } \sigma=c\left[\Gamma\left(1+\frac{2}{k}\right)-\Gamma^{2}\left(1+\frac{1}{k}\right)\right]^{\frac{1}{2}} \\
\frac{\sigma}{\bar{v}}=\sqrt{\frac{\Gamma\left(1+\frac{2}{k}\right)}{\left[\Gamma\left(1+\frac{1}{k}\right)\right]^{2}}-1}
\end{gathered}
$$

The dimensionless Weibull and scale parameters can be calculated as follows:

$$
\begin{aligned}
& k=\left(\frac{0.9874}{\frac{\sigma}{\bar{v}}}\right)^{1.0983} \\
& \bar{v}=c \Gamma\left(1+\frac{1}{k}\right)
\end{aligned}
$$

where $\Gamma()$ is the Gamma function expressed by:

The average wind speed can be expressed as a function of Weibull scale parameter $(c)$ and dimensionless Weibull shape parameter $(k)$ derived from the Gamma function mentioned in Eq. (12).

$$
\Gamma(x)=\int_{0}^{\infty} y^{x-1} e^{-y} \mathrm{~d} y
$$

where $y=\left(\frac{v}{c}\right)^{k}$ and $\frac{v}{c}=y^{x-1} ; \quad x=1+\frac{1}{k}$ after few transformations

$\bar{v}=c+\Gamma\left(1+\frac{1}{k}\right)=0.8525+0.0135 k+e^{-[2+3(k-1)]}$

\section{Mean standard deviation method (MSDM)}

MSDM is constructive where only the two parameters such as mean wind speed and standard deviations are available. It is well known as empirical method and could be considered as a unique case of MOM method, Weibull shape and scale parameters are estimated by:

$$
\begin{aligned}
& k=\left(\frac{\sigma}{\bar{v}}\right)^{-1.086} \\
& c=\frac{\bar{v}}{\Gamma\left(1+\frac{1}{k}\right)}
\end{aligned}
$$

where $\sigma$ is the standard deviation and $\bar{v}$ is the mean wind speed (in meter per second). Alternatively, Weibull scale parameter can be projected from the following expression given by:

$$
c=\frac{\bar{v} k^{2.6674}}{0.184+0.816 k^{2.73855}}
$$




\section{Statistical inaccuracy analysis/goodness of fit}

To find the best method for analysis, several statistical tools were used by the previous researchers to analyze the efficiency of above-mentioned methods. The following tests are as follows (Mohammadi and Mostafaeipour 2013; Costa Rocha et al. 2012; Justus and Mikhail 1976):

(a) Relative percentage of error (RPE)

$$
\mathrm{RPE}=\left(\frac{x_{i, w}-y_{i, m}}{y_{i, m}}\right) \times 100 \%
$$

(b) Root-mean square error (RMSE)

$$
\mathrm{RMSE}=\left[\frac{1}{N} \sum_{i=1}^{n}\left(y_{i, m}-x_{i, w}\right)^{2}\right]^{\frac{1}{2}}
$$

(c) Mean percentage error (MPE)

$$
\mathrm{MPE}=\frac{1}{N} \sum_{i=1}^{n}\left(\frac{x_{i, w}-y_{i, m}}{y_{i, m}}\right) \times 100 \%
$$

(d) Absolute mean percentage error (AMPE)

$$
\mathrm{AMPE}=\frac{1}{N} \sum_{i=1}^{n}\left|\frac{x_{i, w}-y_{i, m}}{y_{i, m}}\right| \times 100 \%
$$

(e) Chi-square error

$$
\chi^{2}=\frac{\sum_{i=1}^{n}\left(y_{i, m}-x_{i, w}\right)^{2}}{x_{i, w}}
$$

(f) Kolmogorov-Smirnov test

$$
Q_{95}=\frac{1.36}{\sqrt{N}}
$$

(g) Analysis of variance (or) regression coefficient

$$
R^{2}=\frac{\sum_{i=1}^{n}\left(y_{i, m}-z_{i, \bar{v}}\right)^{2}-\sum_{i=1}^{n}\left(y_{i, m}-x_{i, w}\right)^{2}}{\sum_{i=1}^{n}\left(y_{i, m}-z_{i, \bar{v}}\right)^{2}}
$$

where $N$ is the number of wind speed observations; $y_{i, m}$ is the frequency of observation or $i$ th calculated value from measured data; $x_{i, w}$ is the frequency of Weibull or $i$ th calculated value from the Weibull distribution; $z_{i, v}$ is the mean of $i$ th calculated value from measured data. In general, RPE shows the percentage deviation between the calculated values from the Weibull distribution and the calculated values from measured data. Similarly, the MPE shows average of percentage deviation between the calculated values from the Weibull distribution and the calculated values from measured data, and MAPE shows the absolute average of percentage deviation between the calculated values from the Weibull distribution and the calculated values from measured data. Paramount results are obtained when these values are nearest to zero. Regression coefficient $\left(R^{2}\right)$ determines the linear relationship between the calculated values from the Weibull distribution and measured data. The ideal value of regression coefficient is equal to 1 .

\section{Coefficient of variation (COV)}

$\mathrm{COV}$ is defined as the ratio between mean standard deviation to the mean wind speed expressed in terms of percentage. It demonstrates the uncertainty of wind speed and can be expressed as (Ahmed and Mahammed 2012):

$$
\operatorname{COV}(\%)=\frac{\sigma}{\bar{v}} \times 100
$$

where $\sigma$ is the standard deviation and $\bar{v}$ is the mean wind speed in $\mathrm{m} / \mathrm{s}$.

\section{Wind energy potential}

Wind turbine or wind energy conversion system (WECS) is a structure that transforms the kinetic energy of the incoming air stream into electrical energy. The performance of a wind turbine is primarily characterized by the manner in which the main indicator of power varies with wind speed. In general, the electrical power output of a model wind turbine is commonly rely on cut-in, rated and cut-off wind speeds. Accurate models of power curve serve as an important tool in wind power forecasting. But the theoretical wind energy per unit area for a given time period $T$ based on the Weibull probability functions, given by (Tian 2011):

$$
E_{\mathrm{w}}=\frac{1}{2} \rho c^{3} \Gamma\left(1+\frac{3}{k}\right) T
$$

where $\rho$ is the air density (assumed to be $1.225 \mathrm{~kg} / \mathrm{m}^{3}$ ).

The analogous energy based on actual time-series data can be obtained by:

$$
E_{\mathrm{a}}=\frac{1}{2} \rho \overline{v^{3}} T
$$

where $\overline{v^{3}}$ is the mean of wind speed cubes.

\section{Results and discussion}

In this investigation, an effort is made to assess the precision concerning the four statistical methods. True mean wind speed data observed at four selected experiencing dissimilar weather conditions are used in the subsequent calculations, i.e., Chercher, Maychew, Mekele and Senkata. Figures 1, 2, 3, 4 show the monthly variations of Weibull distributions generated by four statistical 


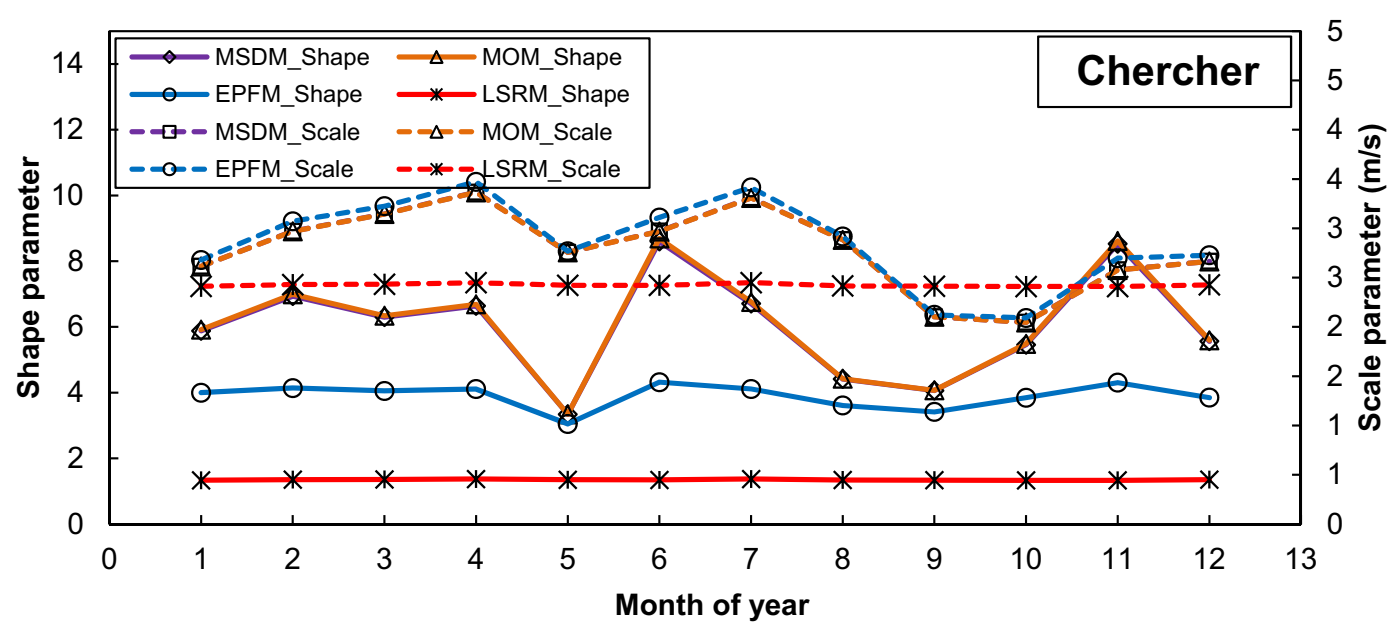

Fig. 1 Weibull scale and shape factors designed by statistical approaches at Chercher

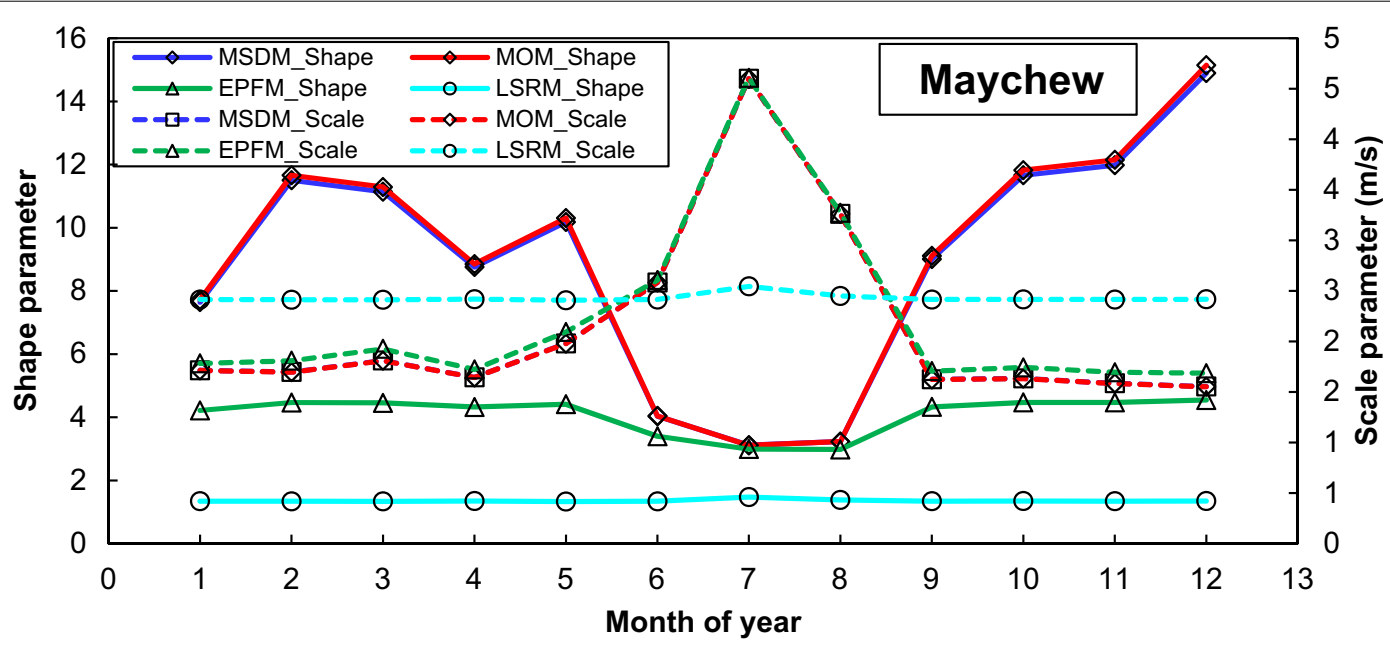

Fig. 2 Weibull scale and shape factors designed by statistical approaches at Maychew

approaches considered for Weibull shape and scale parameters at selected locations. It can be seen that, the divergence for shape parameters and the methods is more significant than that of scale parameters. Dimensionless Weibull shape parameters observed less significant values obtained from EPFM and LSRM. The consistency is arrived at Weibull scale parameters and both the MOM and MSDM present comparable range of Weibull shape and scale parameters.

To scrutinize the performance of the four statistical methods aforementioned in estimating Weibull parameters, a model of cross verification has been anticipated. Tables 2, 3, 4, 5 catalog the expressive statistics of wind speed, which reveal evident variation for different time periods. The speed range can be represented as the discrepancy between the maximum and minimum wind speed. Mean wind speeds are ranging between 3.147 and $1.360 \mathrm{~m} / \mathrm{s}$ at Chercher. Furthermore locations Maychew, Mekele and Senkata are ranging between 3.147 and $1.889 \mathrm{~m} / \mathrm{s}$ correspondingly. Likewise standard deviations are identical at Chercher and Senkata (i.e., 0.341$0.814 \mathrm{~m} / \mathrm{s}$ ), slightly elevated at Maychew and Mekele. Skewness values are ranging between -0.270 and 1.907; and Kurtosis values are ranging between -0.393 and $4.264,-0.366$ and $4.554,-0.481$ and 9.582 and -1.743 and 9.132 at Chercher, Maychew, Mekele and Senkata, respectively. The critical values at $95 \%$ confident level in Kolmogorov-Smirnov test $\left(Q_{95}\right)$ are 0.086 and 0.088 for months with 31 days and 30 days, respectively. At the end, the max-error in CDF never exceeds the corresponding 


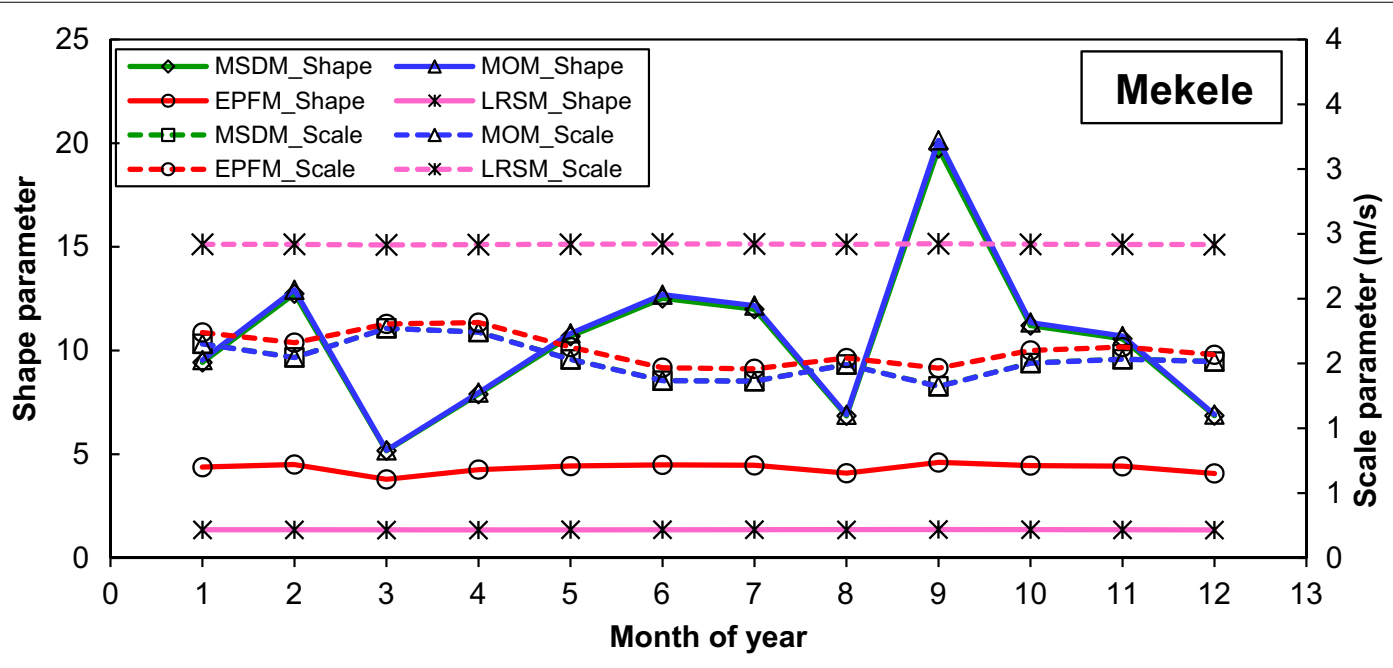

Fig. 3 Weibull scale and shape factors designed by statistical approaches at Mekele

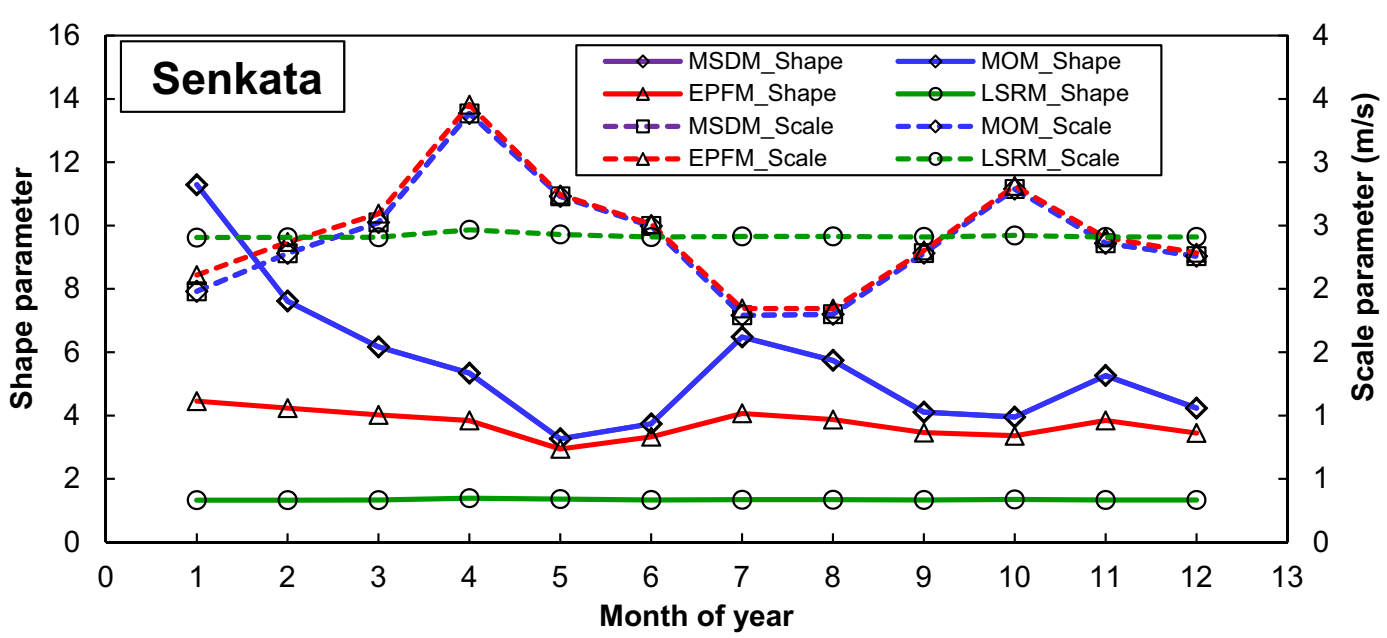

Fig. 4 Weibull scale and shape factors designed by statistical approaches at Senkata

significant values implying that the technique proposed is applicable to generate the variables required in selection of feasible site for generation potential wind energy from turbines.

The precision of four statistical methods observed at four locations experiencing almost similar weather conditions are used in the subsequent calculations, i.e., Chercher, Maychew, Mekele and Senkata. Figures 5, 6, 7, 8 present the histograms and comparison of Weibull probability functions of monthly mean wind speeds for four selected locations. As found, for wind data soundly characterized by both Weibull probability density function (PDF) and cumulative distribution function (CDF). The CDF max-errors are less than or near the critical values of $95 \%$ confidence level in Kolmororov-Smirnov test. In all places similar behavior was observed and least square regression method satisfying more precisely than all other methods.

In each station, the above mentioned four methods were used, in order to estimate the Weibull two parameters i.e., shape and scale parameters. These values are averaged and presented in Table 6 . It can be clearly seen that a strong linear relation between the monthly mean Weibull scale parameters $c$ (averages of the four methods, taken from Table 6) and the measured monthly mean wind speeds for four selected locations. The regression coefficients $\left(R^{2}\right)$ values are extremely high and demonstrate an exceptional counterpart of the 
Table 2 Expressive statistics for observed wind speed data at Chercher

\begin{tabular}{|c|c|c|c|c|c|c|c|c|}
\hline Months & $\begin{array}{l}\text { Data } \\
\text { observations }\end{array}$ & $\begin{array}{l}\text { Wind speed } \\
\text { range }(\mathrm{m} / \mathrm{s})\end{array}$ & Mean $(\mathrm{m} / \mathrm{s})$ & $\begin{array}{l}\text { Standard } \\
\text { deviation }(\mathrm{m} / \mathrm{s})\end{array}$ & Skewness & Kurtosis & $\begin{array}{l}\text { Power } \\
\text { Density }\left(\mathrm{W} / \mathrm{m}^{2}\right)\end{array}$ & $Q_{95}$ \\
\hline Jan & 248 & 1.850 & 2.425 & 0.474 & -0.270 & -0.393 & 8.730 & 0.086 \\
\hline Feb & 224 & 1.810 & 2.786 & 0.468 & 0.570 & 0.962 & 13.238 & 0.091 \\
\hline Mar & 248 & 2.310 & 2.931 & 0.539 & 0.230 & 0.498 & 15.422 & 0.086 \\
\hline Apr & 240 & 2.110 & 3.147 & 0.551 & 0.076 & -0.954 & 19.097 & 0.088 \\
\hline May & 248 & 2.910 & 2.471 & 0.814 & 0.861 & -0.388 & 9.240 & 0.086 \\
\hline June & 240 & 1.500 & 2.827 & 0.390 & -0.253 & -0.591 & 13.842 & 0.088 \\
\hline July & 248 & 2.260 & 3.096 & 0.536 & 0.337 & -0.191 & 18.173 & 0.086 \\
\hline Aug & 248 & 2.190 & 2.626 & 0.669 & 0.038 & -1.158 & 11.091 & 0.086 \\
\hline Sep & 240 & 1.860 & 1.905 & 0.524 & 0.913 & 0.169 & 4.234 & 0.088 \\
\hline Oct & 248 & 1.750 & 1.889 & 0.396 & 1.347 & 2.126 & 4.126 & 0.086 \\
\hline Nov & 240 & 1.360 & 2.452 & 0.341 & 0.258 & -0.291 & 9.031 & 0.088 \\
\hline Dec & 248 & 2.230 & 2.463 & 0.507 & 1.907 & 4.264 & 9.149 & 0.086 \\
\hline Feb-Apr & 712 & 2.077 & 2.955 & 0.519 & 0.292 & 0.169 & 15.798 & 0.051 \\
\hline May-July & 736 & 2.223 & 2.798 & 0.580 & 0.315 & -0.390 & 13.416 & 0.050 \\
\hline Aug-Oct & 736 & 1.933 & 2.140 & 0.530 & 0.766 & 0.379 & 6.001 & 0.050 \\
\hline Nov-Jan & 736 & 2.002 & 2.446 & 0.441 & 0.631 & 1.193 & 8.969 & 0.050 \\
\hline Annual & 5840 & 3.010 & 2.585 & 0.517 & 0.501 & 0.338 & 135.372 & 0.087 \\
\hline
\end{tabular}

Table 3 Expressive statistics for observed wind speed data at Maychew

\begin{tabular}{|c|c|c|c|c|c|c|c|c|}
\hline Months & $\begin{array}{l}\text { Data } \\
\text { observations }\end{array}$ & $\begin{array}{l}\text { Wind speed } \\
\text { range }(\mathrm{m} / \mathrm{s})\end{array}$ & Mean $(\mathrm{m} / \mathrm{s})$ & $\begin{array}{l}\text { Standard } \\
\text { deviation }(\mathrm{m} / \mathrm{s})\end{array}$ & Skewness & Kurtosis & $\begin{array}{l}\text { Power } \\
\text { Density }\left(\mathrm{W} / \mathrm{m}^{2}\right)\end{array}$ & $Q_{95}$ \\
\hline Jan & 248 & 1.110 & 1.619 & 0.249 & 0.769 & 1.401 & 2.597 & 0.086 \\
\hline Feb & 224 & 0.580 & 1.649 & 0.174 & -0.088 & -1.087 & 2.744 & 0.091 \\
\hline Mar & 248 & 0.670 & 1.755 & 0.191 & -0.701 & -0.366 & 3.309 & 0.086 \\
\hline Apr & 240 & 0.720 & 1.567 & 0.212 & 0.147 & -1.196 & 2.356 & 0.088 \\
\hline May & 248 & 1.030 & 1.906 & 0.225 & -0.120 & 0.990 & 4.244 & 0.086 \\
\hline June & 240 & 2.390 & 2.339 & 0.648 & 0.935 & -0.062 & 7.840 & 0.088 \\
\hline July & 248 & 4.960 & 4.110 & 1.443 & 0.062 & -0.812 & 42.516 & 0.086 \\
\hline Aug & 248 & 4.240 & 2.919 & 0.992 & 0.861 & 1.148 & 15.230 & 0.086 \\
\hline Sep & 240 & 0.890 & 1.552 & 0.205 & 1.279 & 1.767 & 2.288 & 0.088 \\
\hline Oct & 248 & 0.610 & 1.588 & 0.165 & -0.151 & -1.014 & 2.451 & 0.086 \\
\hline Nov & 240 & 0.820 & 1.545 & 0.157 & 1.488 & 4.554 & 2.257 & 0.088 \\
\hline Dec & 248 & 0.560 & 1.537 & 0.128 & 0.436 & 0.532 & 2.225 & 0.086 \\
\hline Feb-Apr & 712 & 0.657 & 1.657 & 0.192 & -0.214 & -0.883 & 2.785 & 0.051 \\
\hline May-July & 736 & 2.793 & 2.785 & 0.772 & 0.292 & 0.039 & 13.233 & 0.050 \\
\hline Aug-Oct & 736 & 1.913 & 2.019 & 0.454 & 0.663 & 0.633 & 5.044 & 0.050 \\
\hline Nov-Jan & 736 & 1.939 & 1.567 & 0.178 & 0.898 & 2.162 & 2.356 & 0.050 \\
\hline Annual & 5840 & 5.450 & 2.007 & 0.399 & 0.410 & 0.488 & 90.058 & 0.087 \\
\hline
\end{tabular}

linear model $\left(0.993<R^{2}<0.999\right)$. Figure 9 shows the linear relationship between Weibull scale parameter and monthly mean observed values at Chercher, Maychew, Mekele and Senkata respectively. The maximum regression coefficient (i.e., 0.999) was observed at Maychew and the other three locations illustrate regression coefficient of 0.993 . At last, the correlation between monthly scale parameter, $c$ and the measured mean monthly wind speed was examined in the selected locations and was found linear, with a slope directly proportional to the average of the monthly scale parameters $k$ of the location. 
Table 4 Expressive statistics for observed wind speed data at Mekele

\begin{tabular}{|c|c|c|c|c|c|c|c|c|}
\hline Months & $\begin{array}{l}\text { Data } \\
\text { observations }\end{array}$ & $\begin{array}{l}\text { Wind speed } \\
\text { range }(\mathrm{m} / \mathrm{s})\end{array}$ & Mean $(\mathrm{m} / \mathrm{s})$ & $\begin{array}{l}\text { Standard } \\
\text { deviation }(\mathrm{m} / \mathrm{s})\end{array}$ & Skewness & Kurtosis & $\begin{array}{l}\text { Power } \\
\text { Density }\left(\mathrm{W} / \mathrm{m}^{2}\right)\end{array}$ & $Q_{95}$ \\
\hline Jan & 248 & 0.620 & 1.582 & 0.200 & -0.406 & -1.112 & 2.427 & 0.086 \\
\hline Feb & 224 & 0.490 & 1.514 & 0.145 & 0.080 & -0.935 & 2.124 & 0.091 \\
\hline Mar & 248 & 1.280 & 1.629 & 0.359 & 0.975 & 0.246 & 2.648 & 0.086 \\
\hline Apr & 240 & 1.010 & 1.649 & 0.246 & 0.088 & -0.032 & 2.749 & 0.088 \\
\hline May & 248 & 0.530 & 1.481 & 0.167 & 0.293 & -1.112 & 1.989 & 0.086 \\
\hline June & 240 & 0.400 & 1.337 & 0.131 & 1.799 & 1.691 & 1.465 & 0.088 \\
\hline July & 248 & 0.620 & 1.329 & 0.135 & 2.937 & 9.582 & 1.438 & 0.086 \\
\hline Aug & 248 & 0.540 & 1.398 & 0.238 & 2.264 & 5.453 & 1.674 & 0.086 \\
\hline Sep & 240 & 0.370 & 1.337 & 0.086 & 1.796 & 4.043 & 1.462 & 0.088 \\
\hline Oct & 248 & 0.520 & 1.458 & 0.158 & 0.611 & -0.775 & 1.897 & 0.086 \\
\hline Nov & 240 & 0.560 & 1.481 & 0.169 & 0.736 & -0.481 & 1.989 & 0.088 \\
\hline Dec & 248 & 1.040 & 1.420 & 0.241 & 2.681 & 7.293 & 1.755 & 0.086 \\
\hline Feb-Apr & 712 & 0.927 & 1.597 & 0.250 & 0.381 & -0.240 & 2.497 & 0.051 \\
\hline May-July & 736 & 0.517 & 1.382 & 0.144 & 1.676 & 3.387 & 1.618 & 0.050 \\
\hline Aug-Oct & 736 & 0.477 & 1.397 & 0.160 & 1.557 & 2.907 & 1.672 & 0.050 \\
\hline Nov-Jan & 736 & 0.538 & 1.495 & 0.204 & 1.004 & 1.900 & 2.045 & 0.050 \\
\hline Annual & 5840 & 1.310 & 1.468 & 0.190 & 1.155 & 1.989 & 23.618 & 0.018 \\
\hline
\end{tabular}

Table 5 Expressive statistics for observed wind speed data at Senkata

\begin{tabular}{|c|c|c|c|c|c|c|c|c|}
\hline Months & $\begin{array}{l}\text { Data } \\
\text { observations }\end{array}$ & $\begin{array}{l}\text { Wind speed } \\
\text { range }(\mathrm{m} / \mathrm{s})\end{array}$ & Mean $(\mathrm{m} / \mathrm{s})$ & $\begin{array}{l}\text { Standard } \\
\text { deviation }(\mathrm{m} / \mathrm{s})\end{array}$ & Skewness & Kurtosis & $\begin{array}{l}\text { Power } \\
\text { Density }\left(\mathrm{W} / \mathrm{m}^{2}\right)\end{array}$ & $Q_{95}$ \\
\hline Jan & 248 & 0.850 & 1.921 & 0.206 & 0.014 & -0.104 & 4.342 & 0.086 \\
\hline Feb & 224 & 1.470 & 2.152 & 0.332 & -0.249 & 0.063 & 6.101 & 0.091 \\
\hline Mar & 248 & 1.470 & 2.348 & 0.440 & 0.597 & -0.564 & 7.931 & 0.086 \\
\hline Apr & 240 & 2.570 & 3.119 & 0.667 & 0.805 & -0.187 & 18.582 & 0.088 \\
\hline May & 248 & 3.200 & 2.446 & 0.822 & 1.435 & 1.789 & 8.960 & 0.086 \\
\hline June & 240 & 1.960 & 2.251 & 0.668 & 0.130 & -1.743 & 6.983 & 0.088 \\
\hline July & 248 & 1.170 & 1.672 & 0.299 & 0.771 & 0.794 & 2.862 & 0.086 \\
\hline Aug & 248 & 1.770 & 1.666 & 0.333 & 2.366 & 9.132 & 2.833 & 0.086 \\
\hline Sep & 240 & 1.770 & 2.068 & 0.563 & 0.504 & -1.073 & 5.418 & 0.088 \\
\hline Oct & 248 & 2.720 & 2.522 & 0.712 & 0.947 & 0.424 & 9.826 & 0.086 \\
\hline Nov & 240 & 1.940 & 2.173 & 0.471 & 0.292 & -0.037 & 6.282 & 0.088 \\
\hline Dec & 248 & 2.200 & 2.051 & 0.543 & 1.442 & 1.491 & 5.285 & 0.086 \\
\hline Feb-Apr & 712 & 1.837 & 2.540 & 0.480 & 0.384 & -0.229 & 10.032 & 0.051 \\
\hline May-July & 736 & 2.110 & 2.123 & 0.597 & 0.779 & 0.280 & 5.858 & 0.050 \\
\hline Aug-Oct & 736 & 2.087 & 2.085 & 0.536 & 1.272 & 2.828 & 5.555 & 0.050 \\
\hline Nov-Jan & 736 & 1.682 & 2.048 & 0.407 & 0.583 & 0.450 & 5.263 & 0.050 \\
\hline Annual & 5840 & 3.420 & 2.199 & 0.505 & 0.754 & 0.832 & 85.405 & 0.087 \\
\hline
\end{tabular}

The mutability of wind speed can be demonstrated by the coefficient of variation/turbulence intensity. It can be defined as the ration between standard deviation over the wind speed. It is an indicator of turbulence and not an absolute value, which is a very useful indicator in wind turbine operation and design. The monthly mean $\mathrm{COV}$ values are presented in Fig. 10. It can be seen that the coefficient of variation is ranging between 32.930 and $13.896 \%$ at Chercher and Senkata. The other locations, Maychew and Mekele, ranging between 32.930 and $6.992 \%, 32.930$ and $5.715 \%$, respectively. For instance, at Maychew got higher percentage of variation due to the gusty wind existence in 2 months i.e., July and August. In general, the $\mathrm{COV}$ is lower when wind speed is maximum 


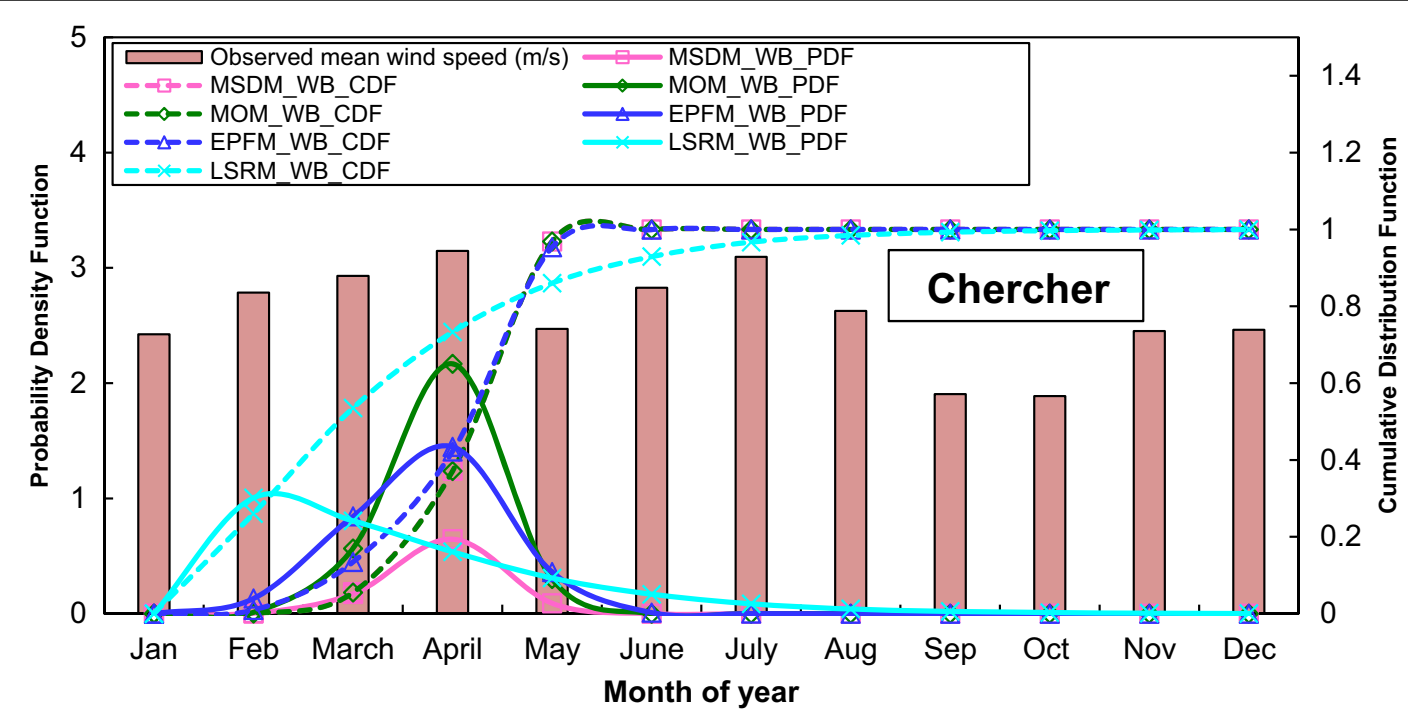

Fig. 5 Histograms and comparison of Weibull probability functions of monthly mean wind speeds observed at Chercher

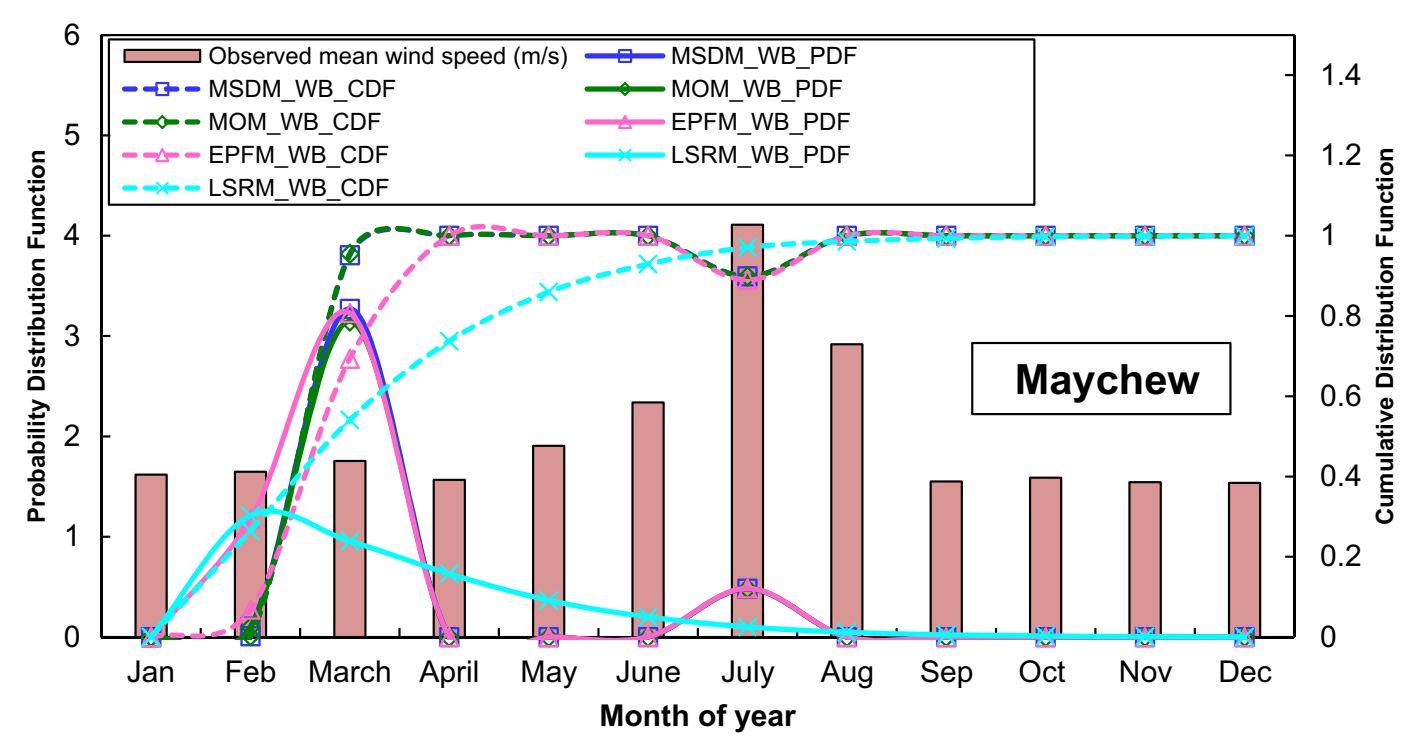

Fig. 6 Histograms and comparison of Weibull probability functions of monthly mean wind speeds observed at Maychew

or vice versa. However, for the sake of complete wind energy potential assessment, wind energy conversion operation, or grid integration, some supplementary information is needed concerning periodicity and more generally time variability of the wind velocity for a given time scale.

In statistical analysis, for judgment of statistical methods to each other and to find out the efficiency of the methods, six statistical tools, i.e., relative percentage error (RPE), root mean square error (RMSE), mean percentage error (MPE), mean absolute percentage error
(MAPE), Chi square error $\left(\chi^{2}\right)$, and analysis of variance or efficiency of the method $\left(R^{2}\right)$ were used. Many researchers have already been used the methods at different geographical locations for wind energy estimation (Lun and Lam 2000). In general, only one column is required to rank the statistical methods, since the above all approaches gave identical virtual results. For more precise diagnosis, authors used these six statistical tools to rank the methods.

The efficiencies of statistical methods (i.e., EPFM, MSDM, MOM and LSRM) at different locations are 


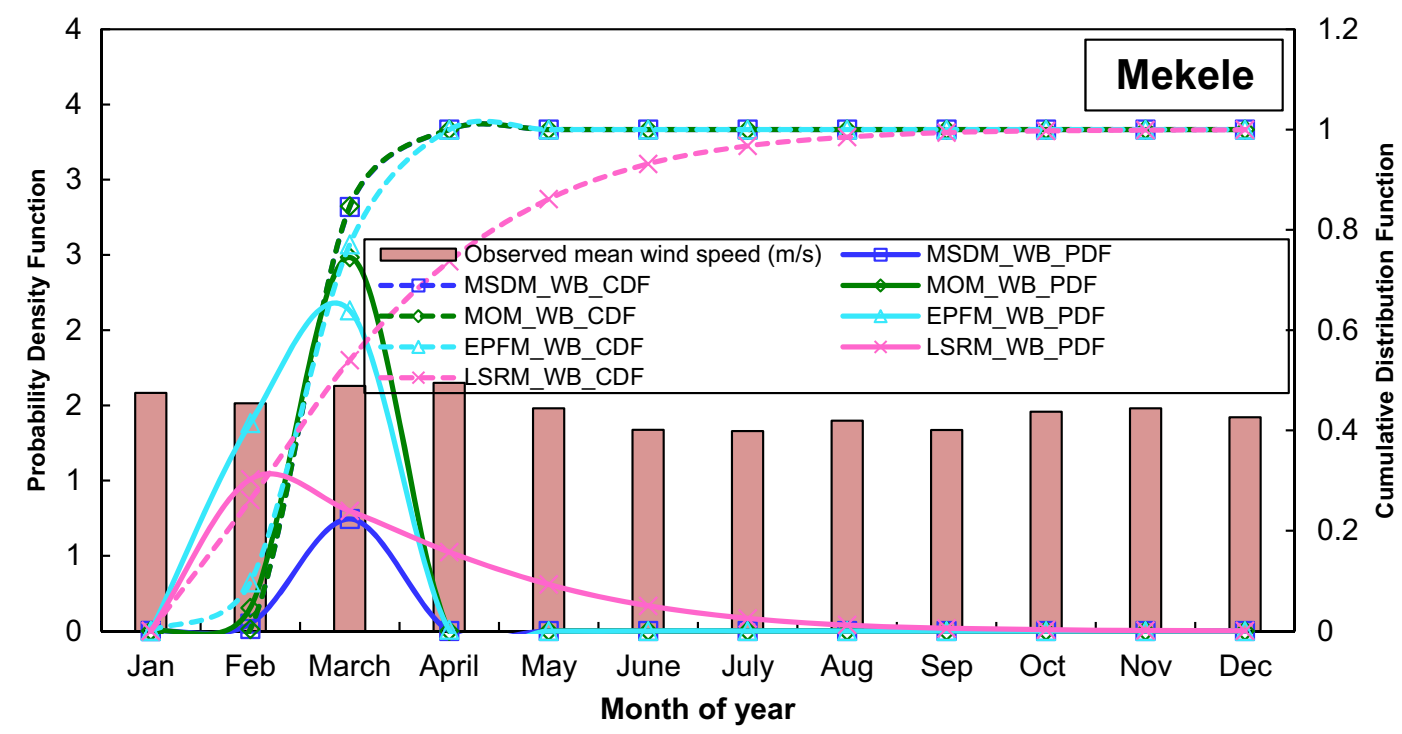

Fig. 7 Histograms and comparison of Weibull probability functions of monthly mean wind speeds observed at Mekele

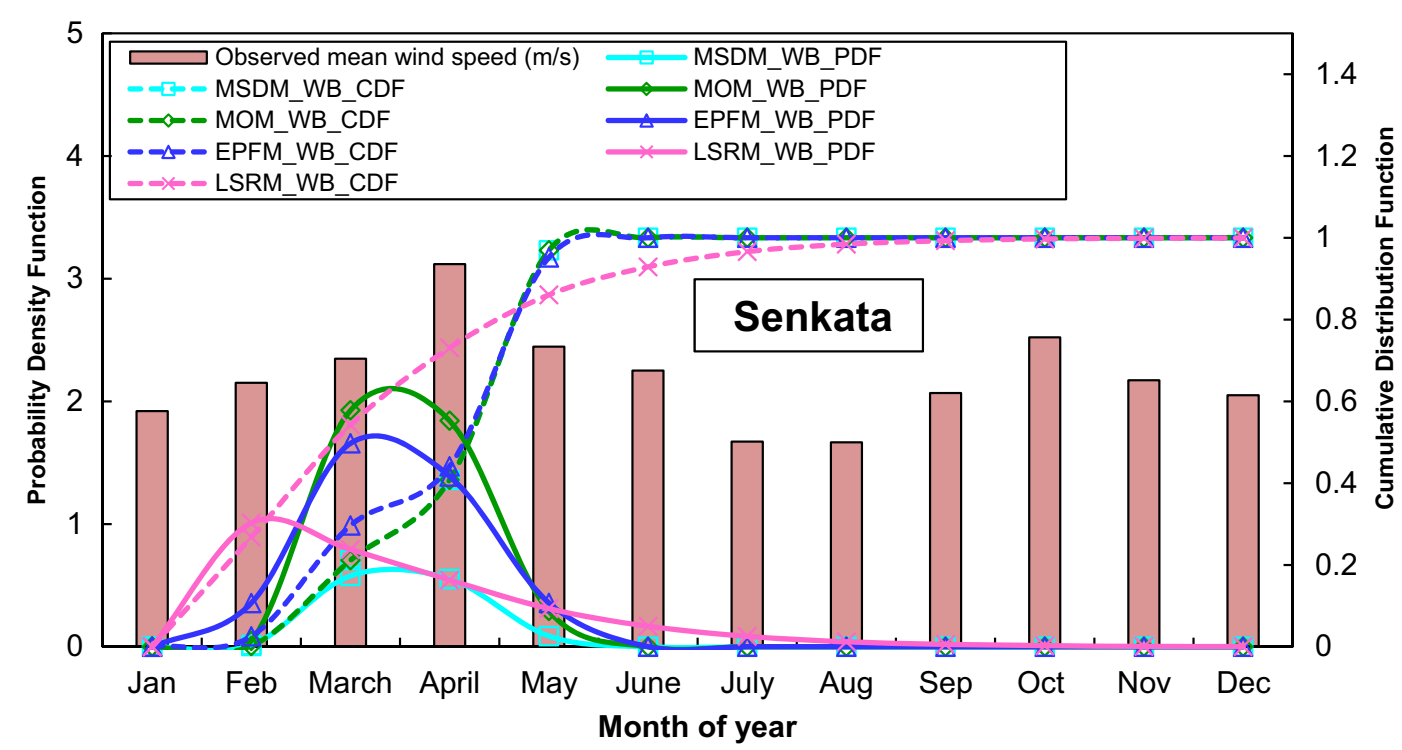

Fig. 8 Histograms and comparison of Weibull probability functions of monthly mean wind speeds observed at Senkata

furnished in Tables 7, 8, 9, 10. Among the selected locations in the study, statistical tools revealed the maximum regression coefficient noticed at Chercher and is presented in Table 7. It can be clearly seen that EPFM $\left(\chi^{2}=13.563, R^{2}=0.802\right)$, LSRM $\left(\chi^{2}=4.227, R^{2}=0.972\right)$, $\operatorname{MOM}\left(\chi^{2}=16.522, R^{2}=0.602\right)$ and $\operatorname{MSDM}\left(\chi^{2}=14.715\right.$, $\left.R^{2}=0.605\right)$ give very close results and showed better performance than other methods. The most important statistical tool i.e., Chi square error, $\chi^{2}=4.227$ and the efficiency of the method is $R^{2}=0.972$, where the best results are obtained when these values are close to zero and unity, respectively.

The test results of four statistical methods and standings of the methods according to their performance and efficiency in evaluation of wind data is summarized in Table 11 . The standings were done by considering minimum error and maximum efficiency according to first to four positions, respectively. In the position standings, 
Table 6 Middling values of monthly mean Weibull parameters estimated from four methods at selected locations

\begin{tabular}{|c|c|c|c|c|c|c|c|c|}
\hline & \multicolumn{2}{|c|}{ Chercher } & \multicolumn{2}{|c|}{ Maychew } & \multicolumn{2}{|l|}{ Mekele } & \multicolumn{2}{|c|}{ Senkata } \\
\hline & $k$ & $c(\mathrm{~m} / \mathrm{s})$ & $k$ & $c(\mathrm{~m} / \mathrm{s})$ & $k$ & $c(\mathrm{~m} / \mathrm{s})$ & $k$ & $c(\mathrm{~m} / \mathrm{s})$ \\
\hline Jan & 4.282 & 2.580 & 5.229 & 1.907 & 6.173 & 1.865 & 7.090 & 2.119 \\
\hline Feb & 4.856 & 2.860 & 7.242 & 1.904 & 7.881 & 1.793 & 5.197 & 2.334 \\
\hline Mar & 4.511 & 2.987 & 7.055 & 1.990 & 3.871 & 1.941 & 4.422 & 2.513 \\
\hline Apr & 4.702 & 3.163 & 5.820 & 1.857 & 5.367 & 1.930 & 3.976 & 3.172 \\
\hline May & 2.769 & 2.676 & 6.556 & 2.115 & 6.825 & 1.778 & 2.709 & 2.659 \\
\hline Jun & 5.738 & 2.868 & 3.203 & 2.547 & 7.764 & 1.657 & 3.034 & 2.478 \\
\hline Jul & 4.739 & 3.120 & 2.673 & 4.088 & 7.494 & 1.652 & 4.592 & 1.960 \\
\hline Aug & 3.447 & 2.775 & 2.704 & 3.061 & 4.797 & 1.736 & 4.174 & 1.964 \\
\hline Sep & 3.221 & 2.185 & 5.946 & 1.843 & 11.462 & 1.634 & 3.251 & 2.319 \\
\hline Oct & 4.030 & 2.148 & 7.325 & 1.856 & 7.089 & 1.757 & 3.153 & 2.703 \\
\hline Nov & 5.694 & 2.565 & 7.486 & 1.820 & 6.758 & 1.778 & 3.926 & 2.384 \\
\hline Dec & 4.089 & 2.621 & 8.983 & 1.802 & 4.797 & 1.754 & 3.312 & 2.303 \\
\hline Annual & 4.340 & 2.712 & 5.852 & 2.232 & 6.690 & 1.773 & 4.070 & 2.409 \\
\hline
\end{tabular}
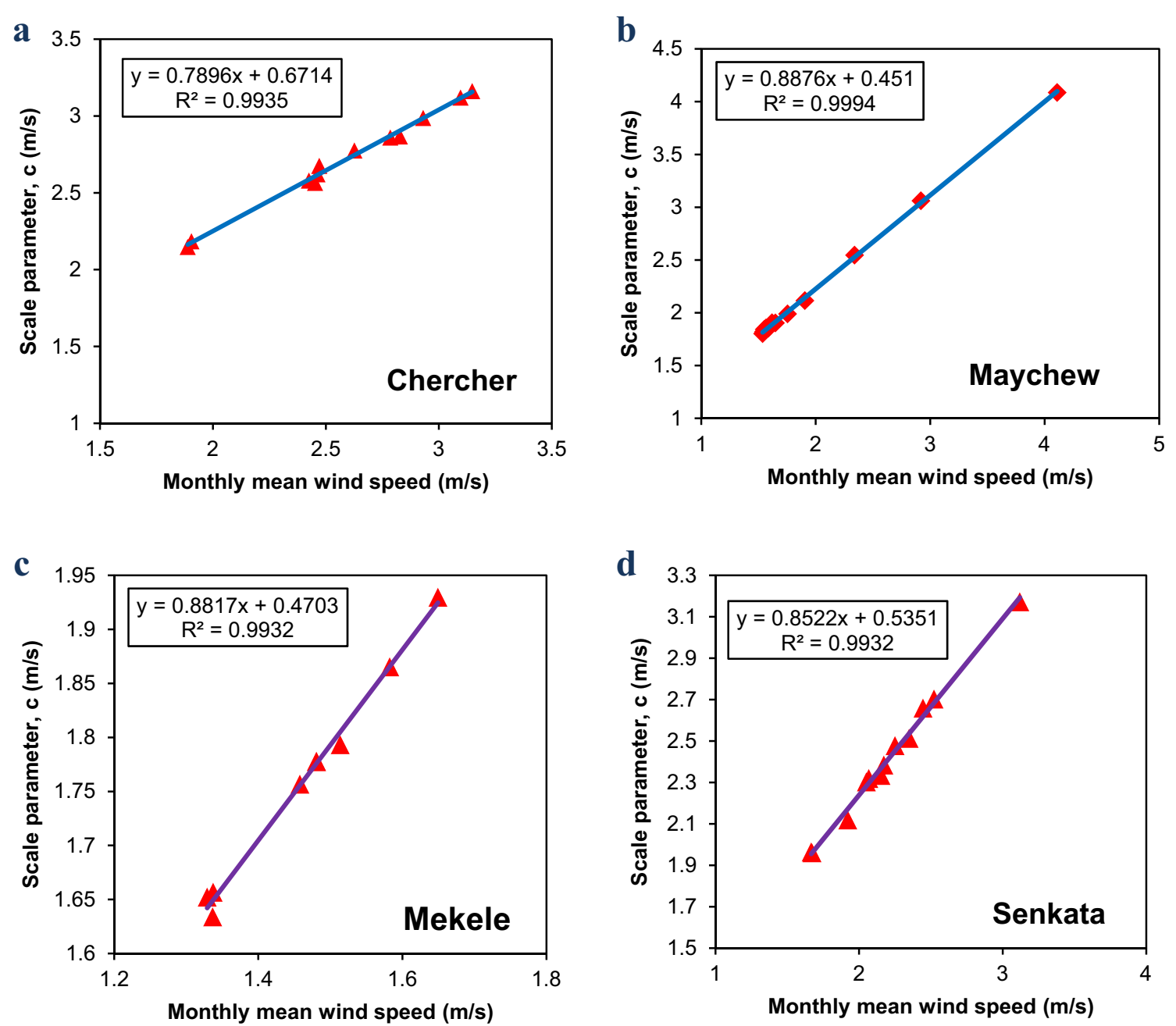

Fig. 9 Relation between the monthly mean Weibull scale parameters $c$ (averages of four methods), and the measured monthly mean wind speeds for a Chercher b Maychew c Mekele and $\mathbf{d}$ Senkata 


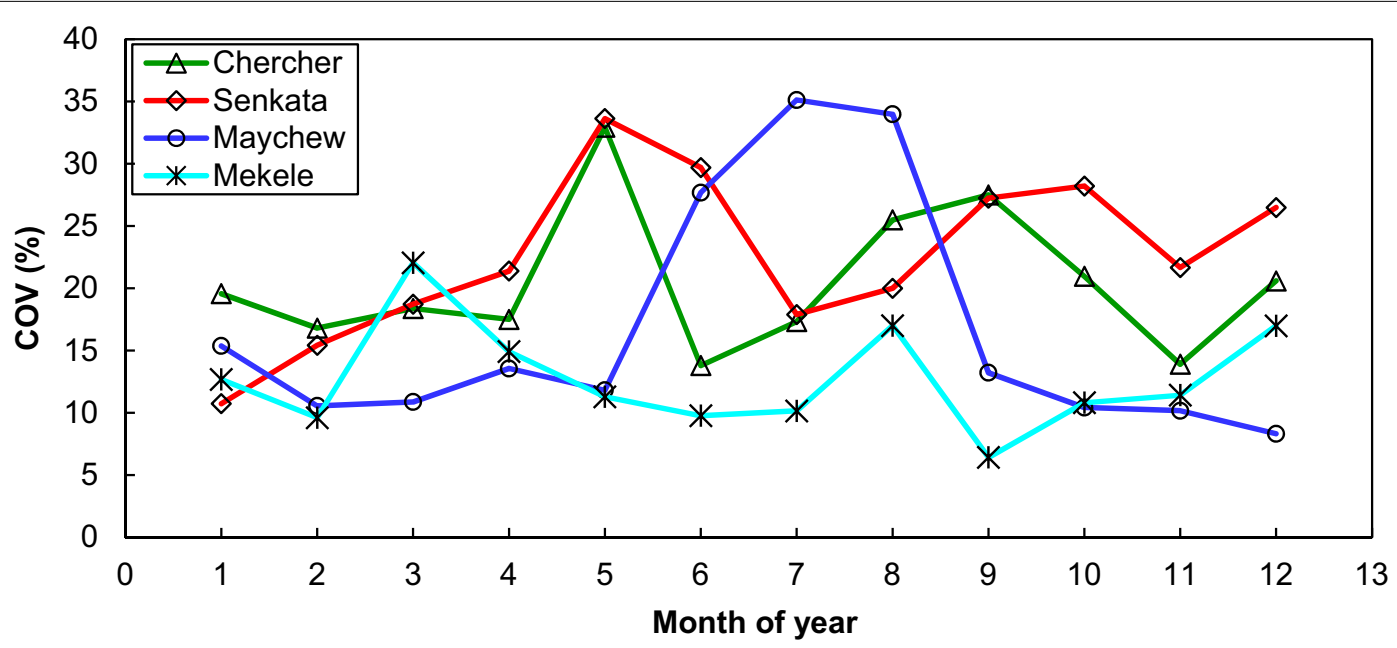

Fig. 10 Monthly COV of selected locations

Table 7 Efficiency of statistical methods used at Chercher

\begin{tabular}{llllllrrr}
\hline Method & $\boldsymbol{k}$ & $\boldsymbol{c}(\mathbf{m} / \mathbf{s})$ & RPE & RMSE & MPE & MAPE & $\boldsymbol{X}^{\mathbf{2}}$ & $\boldsymbol{R}^{\mathbf{2}}$ \\
\hline EPFM & 3.900 & 2.858 & 0.108145 & 0.146590 & 0.013447 & 0.000025 & 13.563 & 0.802 \\
LSRM & 1.346 & 2.424 & 0.040660 & 0.054781 & 0.005040 & 0.000026 & 4.227 & 0.972 \\
MOM & 6.077 & 2.783 & 0.140325 & 0.204084 & 0.017467 & 0.000023 & 16.522 & 0.602 \\
MSDM & 6.036 & 2.784 & 0.139926 & 0.203193 & 0.017417 & 0.000024 & 14.715 & 0.605 \\
\hline
\end{tabular}

Table 8 Efficiency of statistical methods used at Maychew

\begin{tabular}{lllllllrr}
\hline Method & $\boldsymbol{k}$ & $\boldsymbol{c}(\mathbf{m} / \mathbf{s})$ & RPE & RMSE & MPE & MAPE & $\boldsymbol{X}^{\mathbf{2}}$ & $\boldsymbol{R}^{\mathbf{2}}$ \\
\hline EPFM & 4.087 & 2.221 & 0.155112 & 0.237382 & 0.019259 & 0.000029 & 20.393 & 0.401 \\
LSRM & 1.356 & 2.428 & 0.048056 & 0.070872 & 0.005960 & 0.000027 & 5.496 & 0.952 \\
MOM & 9.036 & 2.140 & 0.249320 & 0.434901 & 0.031003 & 0.000028 & 6.889 \\
MSDM & 8.929 & 2.141 & 0.270923 & 0.476823 & 0.033704 & 0.000025 & 11.666 & 0.542 \\
\hline
\end{tabular}

Table 9 Efficiency of statistical methods used at Mekele

\begin{tabular}{llllllllr}
\hline Method & $\boldsymbol{k}$ & $\boldsymbol{c}(\mathbf{m} / \mathbf{s})$ & RPE & RMSE & MPE & MAPE & $\boldsymbol{X}^{\mathbf{2}}$ & $\boldsymbol{R}^{\mathbf{2}}$ \\
\hline EPFM & 4.326 & 1.615 & 0.130576 & 0.254938 & 0.016291 & 0.000108 & 19.846 \\
LSRM & 1.352 & 2.420 & 0.036178 & 0.086152 & 0.004485 & 0.000101 & 0.162 \\
MOM & 10.611 & 1.528 & 0.245858 & 0.614909 & 0.030568 & 0.000083 & 4.717 & 0.853 \\
MSDM & 10.470 & 1.529 & 0.244792 & 0.605580 & 0.030435 & 0.000103 & 1.277 & 0.551 \\
\hline
\end{tabular}

four decimal places have been considered in each value by numerical iteration methods. In this statistical scrutiny, it has been found that the LSRM achieved the first position and the both EPFM and MSDM taken the second position. Although, the MOM got the third position, this method has better performance for low height wind data assessment. The main intention of this statistical analysis is to fulfill the above statistical analysis where we identify the best methods to determine the Weibull distribution and selecting the best wind site by using these best methods. 
Table 10 Efficiency of statistical methods used at Senkata

\begin{tabular}{lllllllrr}
\hline Method & $\boldsymbol{k}$ & $\boldsymbol{c}(\mathbf{m} / \mathbf{s})$ & RPE & RMSE & MPE & MAPE & $\boldsymbol{X}^{\mathbf{2}}$ & $\boldsymbol{R}^{\mathbf{2}}$ \\
\hline EPFM & 3.740 & 2.440 & 0.124385 & 0.169483 & 0.015435 & 0.000023 & 20.368 \\
LSRM & 1.340 & 2.417 & 0.050517 & 0.066387 & 0.006275 & 0.000024 & 5.072 \\
MOM & 5.599 & 2.390 & 0.160906 & 0.235879 & 0.020002 & 0.000024 & 15.513 \\
MSDM & 5.599 & 2.390 & 0.160906 & 0.235879 & 0.020002 & 0.000024 & 15.513 & 0.360 \\
\hline
\end{tabular}

Table 11 Standings of the methods by statistical test results

\begin{tabular}{llllll}
\hline S. no & Statistical methods & Chercher & Maychew & Mekele & Senkata \\
\hline 1 & EPFM & Second & Fourth & Fourth Second \\
2 & LSRM & First & First & First & Third \\
3 & MOM & Fourth & Third & Second & - \\
4 & MSDM & Third & Second & - \\
\hline
\end{tabular}

\section{Conclusions}

In this paper, the scrutiny of four statistical methods in deriving Weibull parameters for wind energy application has been scientifically compared at selected locations in Northern Ethiopia. Statistical diagnosis of the best Weibull distribution methods for wind data analysis is discussed and presented. From the analysis of test results evidently revealed that LSRM presents better performance than other methods. The accuracy of four methods enhances more data numbers. Other methods such as EPFM, MOM and MSDM are the least efficient methods to fit the Weibull distribution curves for the assessment of wind speed data especially for these four selected locations. The maximum regression coefficient noticed at Chercher. The poor class wind power has been noticed in all selected locations. Furthermore, energy density and total energy intensity per unit area has been analyzed by numerical iteration methods. This study offers a new pathway on how to evaluate feasible locations for wind energy assessment which is applicable at any windy sites in any country in the world.

\section{Nomenclature Symbols}

\begin{tabular}{|c|c|}
\hline$\overline{v^{3}}$ & mean of wind speed cubes, $\mathrm{m}^{3} / \mathrm{s}^{3}$ \\
\hline $\bar{v}$ & mean wind speed, $\mathrm{m} / \mathrm{s}$ \\
\hline$c$ & $\begin{array}{l}\text { scale parameter of Weibull distribution func- } \\
\text { tion, } \mathrm{m} / \mathrm{s}\end{array}$ \\
\hline $\mathrm{COV}$ & coefficient of variation \\
\hline EPF & energy pattern factor, dimensionless \\
\hline$E_{\mathrm{w}}$ & 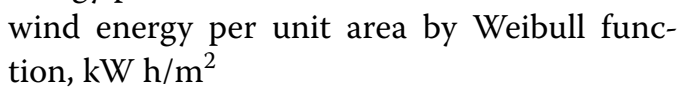 \\
\hline$f(v)$ & Weibull pdf \\
\hline
\end{tabular}

$F(v) \quad$ cumulative Weibull function

$k \quad$ Weibull shape parameter, dimensionless

$N \quad$ total no. of wind speed observations

$R^{2} \quad$ regression coefficient or analysis of variance

$T \quad$ time period, $\mathrm{h}$

$v \quad$ wind speed, $\mathrm{m} / \mathrm{s}$

$x_{i w} \quad$ the frequency of Weibull or $i$ th calculated value from the Weibull distribution

$y_{i, m} \quad$ the frequency of observation or $i$ th calculated value from measured data

$z_{i, v} \quad$ the mean of $i$ th calculated value from measured data

$x^{2} \quad$ Chi-square error

\section{Greek letters}

$\begin{array}{ll}\sigma & \text { standard deviation of wind speed, } \mathrm{m} / \mathrm{s} \\ \Gamma(\text { ) } & \text { gamma function } \\ \rho & \text { air density, } \mathrm{kg} / \mathrm{m}^{3}\end{array}$

Authors' contributions

KSPK collected the wind data and carried out initial analysis. Wind turbine calculations were performed by STNG. "Background" section was drafted by STNG and "Results and discussion" section was jointly drafted by KSPK and STNG.

Both the authors compiled and abridged. Both authors read and approved the final manuscript.

Authors' information

KSPK is working as a Lecturer in Department of Civil Engineering, Wollega University, Nekemte, Ethiopia. He obtained bachelor's degree in Civil Engineering from Osmania University (OU), Hyderabad, and master's degree in Geo-environmental Engineering from JNTUH College of Engineering, Hyderabad. STNG is Associate Professor in Department of Electrical and Computer Engineering, Wollega University, Nekemte, Ethiopia. He obtained bachelor's degree in Science from JVR Government Degree College, Sathupally, Khammam, Telangana state, India and Doctoral Degree in Computer Science and Engineering with specialization in Data Warehousing and Data Mining. 


\section{Author details}

${ }^{1}$ Department of Civil Engineering, College of Engineering and Technology, Wollega University (WU), Nekemte, Oromia Region, Ethiopia. ${ }^{2}$ Department of Electrical and Computer Engineering, College of Engineering and Technology, Wollega University (WU), Nekemte, Oromia Region, Ethiopia.

\section{Acknowledgements}

The authors are grateful to the National Meteorological Agency (NMA),

Mekele, Ethiopia, for their cooperation in providing the raw data.

\section{Competing interests}

The authors declare that they have no competing interests.

Received: 1 July 2015 Accepted: 28 September 2015

Published online: 26 October 2015

\section{References}

Abernethy, R. B. (2002). The new Weibull handbook (4th ed.), North Palm Beach, Florida

Ahmed, S., \& Mahammed, H. (2012). A statistical analysis of wind power density based on the Weibull and Ralyeigh models of "Penjwen Region" Sulaimani/Iraq. Jordan Journal of Mechanical and Industrial Engineering, 6 , 135-140.

Akdag, S. A., Bagiorgas, H. S., \& Mihalakakou, G. (2010). Use of two-component Weibull mixtures in the analysis of wind speed in the Eastern Mediterranean. Applied Energy, 87, 2566-2573.

Akdag, S. A., \& Dinler, A. (2009). A new method to estimate Weibull parameters for wind energy applications. Energy Conversion Management, 50 $1761-1766$.

Akpinar, E. K., \& Akpinar, S. (2004). Determination of the wind energy potential for Maden Elazig, Turkey. Energy Conversion Management, 45, 2901-2914.

Akpinar, E. K., \& Akpinar, S. (2005). An assessment on seasonal analysis of wind energy characteristics and wind turbine characteristics. Energy Conversion and Management, 46, 1848-1867.

Bagiorgas, H. S., Mihalakakou, G., \& Matthopoulos, D. (2008). A statistical analysis of wind speed distributions in the area of western Greece. International Journal of Green Energy, 5(1), 120-137.

Bekele, G., \& Palm, B. (2009). Feasibility study for a standalone solar-wind based hybrid energy system for application in Ethiopia. Applied Energy, 87(2), 487-495.

Benard, A., \& Bos-Levenbach, E. C. (1953). Het uitzetten van waarnemingen op waarschijnlijkdeidspapier (the plotting of observations on probability paper). Statististica Neerlandica, 7, 163-173.

Carta, J. A., Ramirez, P., \& Velazquez, S. (2009). A review of wind speed probability distributions used in wind energy analysis case studies in the Canary Islands. Renewable Sustainable Energy Reviews, 13, 933-955.

Celik, A. N. (2003). A statistical analysis of wind power density based on the Weibull and Rayleigh models at the southern region of Turkey. Renew Energy, 29, 593-604

Chang, T. J., Wu, Y. T., Hsu, H. Y., Chu, C. R., \& Liao, C. M. (2003). Assessment of wind characteristics and wind turbine characteristics in Taiwan. Renewable Energy, 28, 851-871.

Costa Rocha, P. A., de Sousa, R. C., de Andrade, C. F., \& da Silva, M. E. V. (2012) Comparison of seven numerical methods for determining Weibull parameters for wind energy generation in the northeast region of Brazil. Applied Energy, 89, 395-400.

Dorvlo, A. S. S. (2002). Estimating wind speed distribution. Energy Conversion Management, 43, 2311-2318.

Erdem, E., \& Shi, J. (2011). Comparison of bivariate distribution construction approaches for analyzing wind speed and direction data. Wind Energy, 14(1), 27-41.

Ethiopian Electric Power Corporation (EEPCo). (2011). Strategic management and programming. Facts in brief, http://www.eepco.gov.et/files/.../ RPF\%20ENREP\%20Main\%20document.doc.

Ethiopian Electric Power Corporation (EEPCo). (2011). Strategic plan 2011-2025, Addis Ababa. http://www.capitalethiopia.com/ index.php?option=com_content\&view=article\&id=1078:ee pco-envisions-next-25-years\&catid=35: capital\&ltemid $=27$.
Getachew, B., \& Getnet, T. (2012). Feasibility study of small Hydro/PV/Wind hybrid system for off-grid rural electrification in Ethiopia. Applied Energy, $97,5-15$.

International Standards Organization: guide to the expression of uncertainty in measurement, 1st edition (1992). http://www.bipm.org/utils/common/ documents/jcgm/JCGM_100_2008_E.pdf.

Johnson, N. L., \& Kotz, S. (1970). Continuous univariate distributions, vol. 2. Houghton Mifflin.

Jowder, F. A. L. (2009). Wind power analysis and site matching of wind turbine generators in Kingdom of Bahrain. Applied Energy, 86, 538-545.

Junyi, Z., Ergin, E., Gong, L., \& Jing, S. (2010). Comprehensive evaluation of wind speed distribution models: a case study for North Dakota sites. Energy Conversion and Management, 51(7), 1449-1458.

Justus, C. G., Hargraves, W. R., Mikhail, A., \& Graber, D. (1978). Methods for estimating wind speed frequency distributions. Journal of Applied Meteorology, 17, 350-353.

Justus, C., \& Mikhail, A. (1976). Height variation of wind speed and wind distributions statistics. Geophysical Research Letters, 3, 261-264.

Kwon, S. D. (2010). Uncertainty analysis of wind energy potential assessment. Applied Energy, 87, 856-865.

Lai, C. M., \& Lin, T. H. (2006). Technical assessment of the use of a small-scale wind power system to meet the demand for electricity in a land aquafarm in Taiwan. Renew Energy, 31, 877-892.

Lun, I. Y. F., \& Lam, J. C. (2000). A study of Weibull parameters using long-term wind observations. Renewable Energy, 20, 145-153.

Manwell, J. F., McGowan, J. G., \& Rogers, A. L. (2010). Wind energy explained: theory, design and application (2nd ed.). Wiltshire: Wiley.

Mathew, S. (2006). Wind energy: fundamentals, resource analysis and economics. Heidelberg: Springer.

Ministry of Water and Energy (MoWE). (2011). Energy sector mapping and database development (ESMAD), first phase report. http://ergethiopia. com/energy-sector-mapping-and-database-development-esmad/.

Mohammadi, K., \& Mostafaeipour, A. (2013). Using different methods for comprehensive study of wind turbine utilization in Zarrineh, Iran. Energy Conversion Management, 65, 463-470.

Mulugeta, B. A., Aleksandar, S., Dragan, K., \& Slobodan, S. (2013). Wind energy resource development in Ethiopia as an alternative energy future beyond the dominant hydropower. Renewable and Sustainable Energy Reviews, 23, $366-378$.

Paritosh, B. (2011). Weibull distribution for estimating the parameters. Wind Energy Management, publication with In Tech, ISBN: 978-953-307-3361. http://www.intechopen.com/books/wind-energy-management/ weibull-distribution-for-estimating-the-parameters.

Seguro, J. V., \& Lambert, T. W. (2000). Modern estimation of the parameters of the Weibull wind speed distribution for wind energy analysis. Journal of Wind Energy and Industrial Aerodynamics, 85(1), 75-84.

Thiaw, L., Sow, G., Fall, S. S., Kasse, M., Sylla, E., \& Thioye, S. (2010). A neural network based approach for wind resource and wind generators production assessment. Applied Energy, 87, 1744-1748.

Tian, P. C. (2011). Performance comparison of six numerical methods in estimating Weibull parameters for wind energy application. Applied Energy, 88(1), 272-282.

Ucar, A., \& Balo, F. (2009). Investigation of wind characteristics and assessment of wind generation potentiality in Uludag-Bursa, Turkey. Applied Energy, $86,333-339$.

Weibull, W. (1939). A statistical theory of the strength of materials. Ingeniors Vetenskaps Akademiens Handlingar (Royal Swedish Institute for Engineering), 151,1-45.

Weibull, W. (1951). A statistical distribution functions of wide applicability. Journal of Applied Mechanics, Transactions of the ASME, 18, 292-297.

Xiuli, Q., \& Jing, S. (2010). Bivariate modeling of wind speed and air density distribution for long-term wind energy estimation. International Journal of Green Energy, 7(1), 21-37.

World Wind Energy Association (WWEA). (2014). http://www.wwindea.org. Accessed April 2015.

Yong, H. O. U., Yidong, P. E. N. G., Johnson, A. L., \& Jing, S. H. I. (2012). Empirical analysis of wind power potential at multiple heights for North Dakota wind observation sites. Energy Science and Technology, 4(1), 1-12.

Zhou, W., Yang, H. X., \& Fang, Z. H. (2006). Wind power potential and characteristic analysis of the Pearl River Delta region, China. Renew Energy, 31(6), 739-753. 